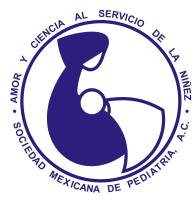

\title{
Fiebre manchada de las Montañas Rocosas en niños. Correlación clínica e histopatológica
}

\author{
Spotted rocky mountain fever in children. Clinical and histopathological correlation
}

\author{
Mariana Guadalupe Ungson-García,* Norberto Gómez-Rivera, ${ }^{\ddagger,+}$ Isaac Albéniz Gómez-Jiménez,* \\ María Guadalupe García-Zarate, * César Omar Gómez-Figueroa, ${ }^{\S}$ Luis Villalobos-García*
}

${ }^{*}$ Hospital Ángeles Mocel, Ciudad de México; ${ }^{\ddagger}$ Hospital Infantil del Estado de Sonora; ${ }^{\S}$ Universidad Durango Santander, Durango, México.

\section{RESUMEN}

Se presentan dos casos clínicos de fiebre manchada de las Montañas Rocosas en niños, con evolución clínica diferente. Un paciente tuvo una evolución satisfactoria, dado que el tratamiento específico se inició dentro de los primeros cinco días de haber iniciado la sintomatología; mientras que el otro paciente presentó una evolución fatal, con necrosis y gangrena en extremidades inferiores. En ambos casos, se confirmó diagnóstico por biopsia de piel mediante la técnica de Pinkerton.

Palabras clave: Fiebre manchada de Montañas Rocosas, Rickettsia rickettsii, biopsia de piel, tinción de Pinkerton, niños.

\section{INTRODUCCIÓN}

El estado de Sonora se ubica en el noroeste de México, la cual es una zona endémica de fiebre manchada de las Montañas Rocosas (FMMR) desde hace décadas. ${ }^{1} \mathrm{La}$ incidencia de infecciones debida a FMMR ha presentado incrementos desde el año 2003 hasta la actualidad, con disminución en la letalidad que pasó de 66 a 14\% en los últimos años. ${ }^{2}$

\footnotetext{
+Correspondencia: NGR, gomez_rivera@yahoo.com.mx Conflicto de intereses: Los autores declaran que no tienen. Citar como: Ungson-García MG, Gómez-Rivera N, Gómez-Jiménez IA, García-Zarate MG, Gómez-Figueroa CO, Villalobos-García L. Fiebre manchada de las Montañas Rocosas en niños. Correlación clínica e histopatológica. Rev Mex Pediatr. 2020; 87(4): 142-145. https://dx.doi.org/10.35366/95824
}

\begin{abstract}
Two clinical cases of Rocky Mountain spotted fever in children with different clinical course are presented. One patient had a satisfactory evolution, since the specific treatment was initiated within the first five days of initiating the symptoms; while the other patient had a fatal outcome, with necrosis and gangrene in lower extremities. In both cases, diagnosis was confirmed by skin biopsy using the technique of Pinkerton.
\end{abstract}

Keywords: Rocky Mountain spotted fever, Rickettsia rickettsii, skin biopsy, Pinkerton stain, children.

La FMMR es una infección ocasionada por la bacteria Rickettsia rickettsii, y transmitida al humano por la mordedura de la garrapata (Rhipicephalus sanguineus) del perro. ${ }^{3,4}$ Las lesiones dérmicas observadas en la FMMR, que habitualmente aparecen a partir del tercer día como exantema petequial, progresan como vasculitis, necrosis y gangrena. Las alteraciones dermatológicas se deben al daño a las células endoteliales de los pequeños vasos sanguíneos. ${ }^{5}$

En esta ocasión publicamos dos casos clínicos atendidos en un hospital de niños en Sonora, México, donde ambos fueron niños que tuvieron lesiones dérmicas, pero con evolución diferente. En ambos pacientes se pudo correlacionar el cuadro clínico con los hallazgos por histopatológica de biopsia de piel mediante tinción de Pinkerton. ${ }^{6,7}$ 


\section{PRESENTACIÓN DE LOS CASOS}

\section{Caso clínico 1}

Paciente masculino de cuatro años de edad, originario de Hermosillo, Sonora, previamente sano, sin antecedentes personales patológicos, pero en contacto con perros con garrapatas.

Inicia su padecimiento cuatro días previos, con mal estado general manifestado por cefalea, náuseas, vómitos, dolor osteomuscular, acompañándose de fiebre no cuantificada; acude con médico particular quien prescribe reposo, analgésico y antibióticos (amoxacilina). Al no presentar mejoría, acude al Hospital Infantil del Estado de Sonora.

A su ingreso se detectó con taquicardia (110 latidos/ minuto), fiebre $\left(39.1^{\circ} \mathrm{C}\right)$, taquipnea (36 por minuto) e hipotensión (T/A 60/40; PAM $46 \mathrm{mmHg}$ ). A la exploración física se encontraba consciente, reactivo y Glasgow íntegro (15 puntos). Además, presentaba exantema petequial (que no desaparecía a la digito-presión) en extremidades, dorso de manos, tórax y abdomen ( $\mathrm{Fi}$ gura 1). Exámenes de laboratorio al ingreso: $\mathrm{Hb} 10.70$ $\mathrm{g} / \mathrm{dL}$, leucocitos $13.84 \times 10^{3} / \mu \mathrm{L}$, neutrófilos $79.7 \%$, linfocitos $13 \%$, plaquetas $102 \times 10^{3} / \mu \mathrm{L}$, procalcitonina (PCT) $4.68 \mathrm{ng} / \mathrm{mL}$. Lactato sérico $3.5 \mathrm{mmol} / \mathrm{L}$. Mientras que electrolitos séricos, perfil hepático y renal fueron normales. Se solicita RT-PCR para $R$. rickettsii.

Se inició manejo para FMMR según los criterios de Conference International Sepsis Definitions, ${ }^{8}$ con vasopresores, inotrópicos, esteroides, hemoderivados y doxiciclina-ciprofloxacina. ${ }^{9}$

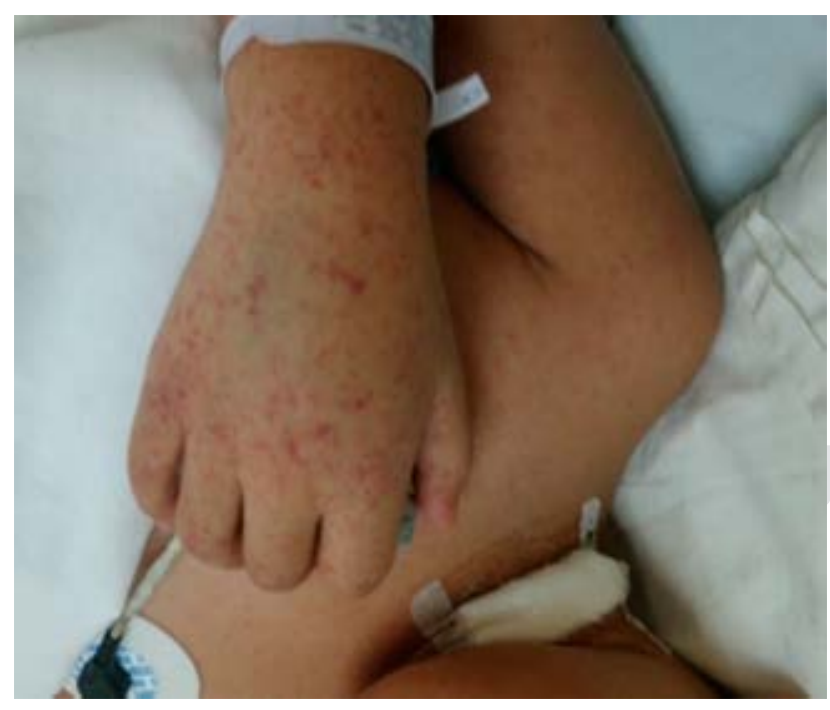

Figura 1: Caso clínico 1. Exantema petequial.

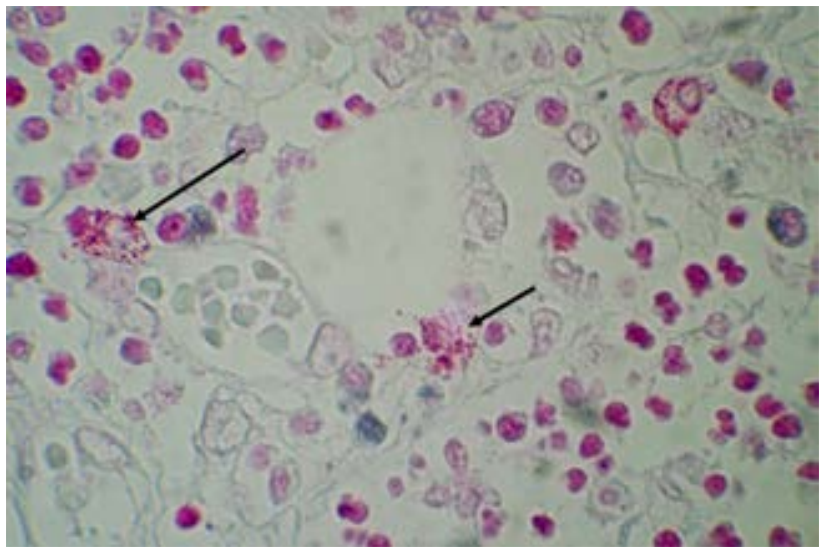

Figura 2: Caso clínico 1. Tinción histopatológica de piel, técnica de Pinkerton, las flechas señalan células endoteliales infestadas con Rickettsia spp., bacilos intracelulares, pleomórficos, en forma de cocos miden $0.1 \mu \mathrm{m}$ de diámetro. Pequeños vasos sanguíneos conservados.

$\mathrm{Al}$ sexto día de evolución, es decir, dos días de haber ingresado, el paciente refiere dolor abdominal y se incrementó el exantema, apareciendo lesiones sugestivas de vasculitis (livedo reticularis y máculas purpúricas). Se toma biopsia de piel y se solicita tinción de Pinkerton al Servicio de Patología.

$\mathrm{Al}$ octavo día de evolución se observó mejoría del estado hemodinámico y aumento de plaquetas $(156 \times$ $10^{3} / \mu \mathrm{L}$ ), suspendiendo el manejo intensivo. Se recibe reporte de patología, donde se informa células epiteliales infestadas por Rickettsia spp., y vaso sanguíneo íntegro (Figura 2). RT-PCR fue positiva para $R$. rickettsii.

Para el día 13 de evolución el paciente seguía mejorando, sin progreso de las lesiones dérmicas. Se solicita al laboratorio estatal IFI (inmunofluorescencia indirecta) específica para $R$. rickettsii, la cual fue positiva (IgM 1: 64).

\section{CASO CLÍNICO 2}

Paciente masculino de ocho años de edad, originario de Hermosillo, Sonora, previamente sano, sin antecedentes de importancia, pero también tenía contacto con perros con garrapatas.

Inicia su padecimiento ocho días previos a su ingreso con fiebre de $40{ }^{\circ} \mathrm{C}$, cefalea, náusea, vómitos y dolor osteomuscular, agregándose exantema al cuarto día. Durante este periodo, acudió a médico particular en tres ocasiones, quien consideró se trataba de faringoamigdalitis, dando tratamiento con paracetamol, 
loratadina, amoxicilina, ceftriaxona y azitromicina durante siete días. Dado que no hubo mejoría llegó a nuestro hospital.

$\mathrm{Al}$ ingreso FC 120 por min, FR 40 por min, temperatura $39{ }^{\circ} \mathrm{C}$, TA $95 / 64$, Sat. $\mathrm{O}_{2} 99 \%$. Se encontraba inquieto, con dificultad respiratoria, escleróticas ictéricas, campos pulmonares con crépitos aislados, abdomen con hiperalgesia generalizada superficial y profunda, borde hepático a $3 \mathrm{~cm}$ debajo del reborde costal. Extremidades con máculas purpúricas confluentes (sugestivas de vasculitis), así como edema de tobillos y muñecas (Figura 3).

$\mathrm{Hb} 14.3 \mathrm{~g} / \mathrm{dL}$, leucocitos de $15,300 \times 10^{3} / \mu \mathrm{L}$, plaquetas $16,000 \times 10^{3} / \mu \mathrm{L}$, TP $18.6 \mathrm{seg}$, TPT $57.2 \mathrm{seg}$, creatinina $3.3 \mathrm{mg} / \mathrm{dL}$, bilirrubinas totales $10.53 \mathrm{mg} / \mathrm{dL}$, TGO 408 U/L, TGP 88 U/L, PCT 45.13 ng/mL, lactato $14.7 \mathrm{mmol} / \mathrm{L}$.

Por el compromiso respiratorio se realizó intubación orotraqueal, y ante la sospecha de FMMR se inició manejo similar al caso previo, solicitando RT-PCR para $R$. rickettsii y toma de biopsia de piel.

Ocho horas después del ingreso se observó que aumentaron las lesiones dérmicas y los ortejos mostraban cambios de coloración. A las 18 horas de ingreso, la vasculitis era generalizada, pero predominando en ex-

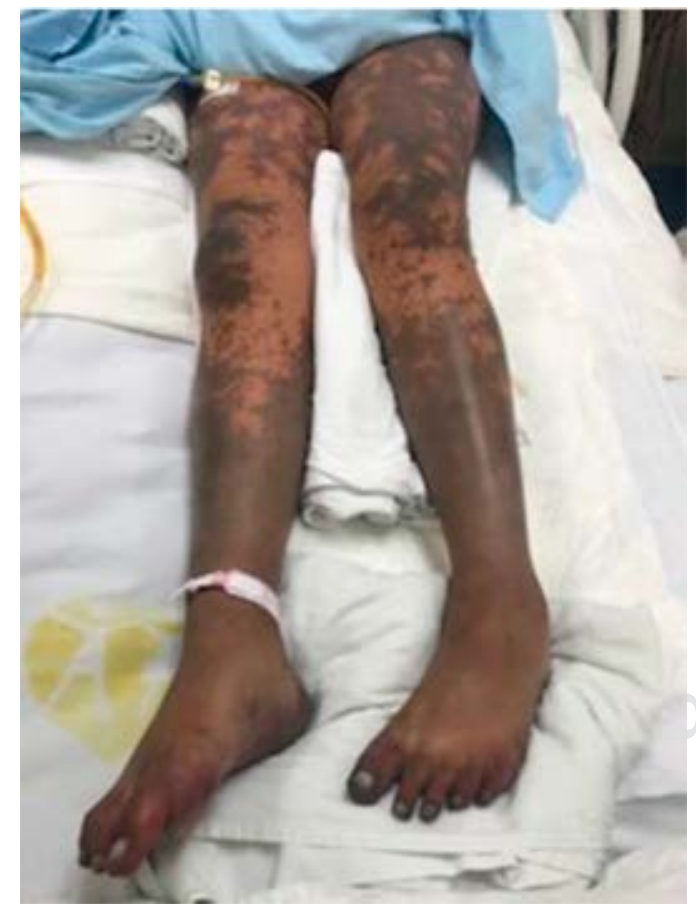

Figura 3: Caso clínico 2. Vasculitis generalizada y necrosis de ortejos.

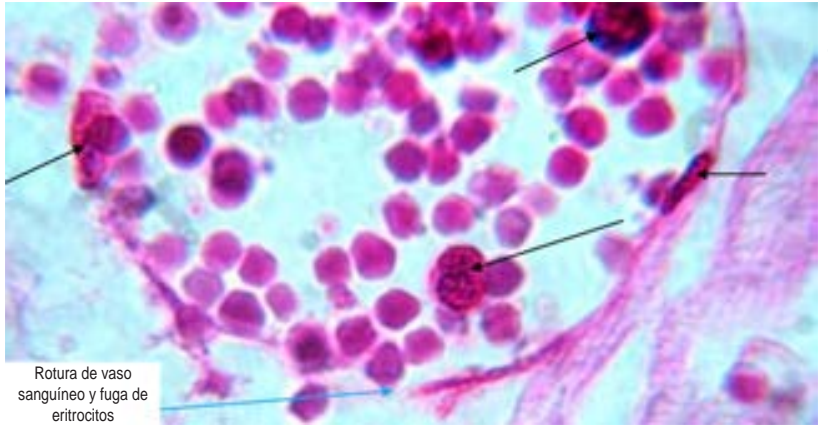

Figura 4: Caso clínico 2. Tinción histopatológica de piel, técnica de Pinkerton, se observan células endoteliales infestadas por Rickettsia spp. (flechas negras), además desgarro del vaso capilar con extravasación de eritrocitos (flecha azul).

tremidades inferiores, dando el aspecto de "manchado". Los ortejos con necrosis. A las 24 horas tiene hipotensión persistente a pesar del manejo con aminas, por lo que momentos después fallece, a pesar de maniobras avanzadas de reanimación.

En el reporte de Patología se describe células epiteliales infestadas por Rickettsia spp., además de endotelio vascular roto con salida de eritrocitos (Figura 4). El resultado de IFI fue reportado como indeterminado.

\section{DISCUSIÓN}

La $R$. rickettsii es la más letal de todas las rickettsias. ${ }^{10,11}$ Es una bacteria Gram negativa, intracelular obligada, incluso se le considera una bacteria parásito ya que, a diferencia de otras bacterias, no contiene genes para la glucólisis anaeróbica o para que participen en la biosíntesis, regulación de los aminoácidos y nucleótidos. De ahí que forzosamente requieren del hospedero para vivir y replicarse. ${ }^{12}$

El diagnóstico temprano (antes de los cinco días) de la FMMR es fundamental, ${ }^{13,14}$ a fin de disminuir la letalidad. Como se describe en los dos pacientes presentados, a pesar de presentar un cuadro clínico similar, el inicio del tratamiento tuvo un papel fundamental en el pronóstico. En el caso 1, el tratamiento se inició durante los primeros cinco días y hubo buena evolución; mientras que en el caso clínico 2, hasta los ocho días se da el tratamiento específico y su evolución fue fatal.

En ambos casos se tomó biopsia de piel, realizando tinción de Pinkerton, con resultados positivos. Este tipo de tinción permite observar la especie de Rickettsia spp., y con las pruebas de RT-PCR e IFI se determina específicamente la especie $R$. rickettsii. 
Además de la identificación de bacteria, en los dos casos que se presentan de FMMR, la biopsia de piel ayudó a disponer de una correlación clínico-patológica. En el caso 1 se documentó que los vasos sanguíneos estaban íntegros (Figura 2), no así en la biopsia del caso clínico 2 (Figura 4) en la cual se observó desgarre y rotura del endotelio vascular, lo que favorece la extravasación de líquidos y elementos sanguíneos, de ahí la explicación del edema de muñecas y tobillos, así como el estadio de choque.

Es importante mencionar que las células epiteliales son altamente especializadas, las cuales, además de ayudar en la regulación de la coagulación, controlan la fibrinólisis y trombosis. Asimismo, participan para modular la actividad de las células musculares de la capa media de los vasos sanguíneos, manteniendo una presión arterial fisiológica. ${ }^{15-17}$

\section{AGRADECIMIENTOS}

Al Dr. Juan Domingo Castillo Aldaco, al proporcionarnos las fotografías de la biopsia de piel.

\section{REFERENCIAS}

1. Gómez N, Álvarez G, García M, Fonseca I, Cano M, Villalobos Let al. Fiebre manchada de las Montañas Rocosas en niños. Informe de 18 casos. Rev Mex Pediatr. 2009; 76(6): 245-250.

2. Gómez N, Gómez I, Fonseca I, García M, Gómez O, Villalobos $L$ et al. Factores relacionados con la mortalidad en niños con fiebre manchada de las montañas rocosas: análisis de 14 años en Sonora, México. Rev Mex Pediatr. 2019; 86(1): 8-12.
3. Walker D, Raoult D. Rickettsia rickettsii and other spotted fever group Rickettsiae. In: Mandell, Bennett, \& Dolin. Principles and practice of infectious diseases. 6th edition; 2005, pp. 2287-2295.

4. Foley J, Tinoco L, Rodriguez M, Estrada J, Fierro M, Mattar E et al. Unbiased Assessment of abundance of Rhipicephalus sanguineus senso lato Ticks. Exposure to spotted fever Group Rickettsia and Risk in Mexicali, México. Am J Trop Med Hyg. 2019; 101: 22-32.

5. Tull R, Ahn C, Daniel A, Yosipovitch G, Strowd L. Retrospective study of Rocky Mountain spotted fever in children. Pediatr Dermatol. 2017; 34: 119-123.

6. Luna G. Manual of histologic staining methods of the armed forces institute of pathology. 3rd ed., HT (ASCP); 1960, pp. 237.

7. Simons J, Gentzkow C. Laboratory methods of the United States Army. 5th ed. Philadelphia, Penn., Lea and Febiger; 1944, pp. 572.

8. Dellinger R. Surviving sepsis campaing. international guidelines for management of severe sepsis and septic shock. Crit Care Med. 2008; 36: 296-227.

9. Gómez N, Fonseca I, García M, Gómez C, Villalobos L. Contraste entre dos esquemas de antibióticos en niños con choque séptico por "fiebre manchada de las Montañas Rocosas". Rev Mex Pediatr. 2014; 81(6): 204-208.

10. Heinzen R, Hayes S, Peacock M, Hackstad T. Directional actin polymerization associated with spotted fever group rickettsia infection of Vero cells. Infect Immun. 1993; 61: 1926-1935.

11. Burgdorfer W, Anacker R, Bird R, Bertram D. Intranuclear growth of Rickettsia rickettsii. J Bacteriol. 1968; 96: 1415-1418.

12. Raoult D, La Scola B, Enea M. A flea-associated rickettsia pathogenic for humans. Emerg Infect Dis. 2001; 7: 73-81.

13. Cunha B. Antibiotic essentials, 7th ed. Royal Oak, MI: Physicians Press, 2008, pp. 442-443.

14. Cunha B. Typhoid fever: the temporal relations of key clinical diagnostic points. Lancet Infect Dis. 2006; 6: 318-320.

15. Broze $\mathrm{G}$. Tissue factor pathway inhibitor and the current concept of blood coagulation. Blood Coagul Fibrinolysis. 1995; 6: 7-13.

16. Aird W. Endothelial cell heterogeneity. Crit Care Med. 2003; 31: S221-229.

17. Duboscq C. Rol de la heterogeneidad endotelial en la regulación de la hemostasia. Acta Bioquim Latinome. 2006; 40(3): 317-325. 